\title{
Precipitação em Maringá-PR: estatísticas descritivas, tendência de longo prazo e probabilidade de eventos extremos diários
}

\section{Rainfall in Maringá-PR: descriptive statistics, long-term trend and probability of daily extreme events}

\author{
Otávio Cristiano Montanher* $\bowtie$ (D), Cíntia Minaki $\bowtie$ (iD \\ Departamento de Geografia, Centro de Ciências Humanas, Letras e Artes, \\ Universidade Estadual de Maringá, Maringá, Paraná, Brasil \\ E-mails: cminaki@uem.br \\ *E-mail para correspondência: otaviocmontanher@yahoo.com.br
}

Recebido (Received): 18/11/2019 Aceito (Accepted): 25/06/2020

\begin{abstract}
Resumo: Este artigo buscou apresentar uma visão geral sobre a precipitação registrada na Estação Climatológica Principal de Maringá (ECPM), no período de 1980 a 2018. Quatro objetivos delinearam a pesquisa: i) obtenção de estatísticas descritivas; ii) avaliação de tendências de longo prazo; iii) avaliação da distribuição de probabilidade da precipitação diária, e iv) análise dos dias consecutivos com chuvas. Além do padrão geral dos períodos úmido e seco, observou-se máximos locais de precipitação em maio e outubro. As tendências de longo prazo foram avaliadas por meio da análise de regressão linear, não se identificando tendências estatísticas significativas. Entretanto, por meio do teste de médias, verificou-se que os anos mais recentes (2013 a 2018) foram mais chuvosos do que o restante da série (1980 a 2012). A distribuição gama foi a que apresentou o melhor ajuste entre os dados analisados e a distribuição teórica. Observou-se que em maio, setembro e outubro os volumes diários estimados são superiores aos observados no restante do ano. $\mathrm{O}$ período com maior número de dias consecutivos de chuva é entre outubro a março. Por outro lado, os maiores volumes por evento acontecem nesses meses e em maio e setembro. Embora tenham acumulados mensais menores do que nos meses de verão, nas estações do outono e da primavera ocorrem chuvas diárias expressivas, cujos extremos são maiores do que no verão. Essa característica relaciona-se à atuação intensificada de sistemas atmosféricos de baixa pressão, principalmente cavados e sistemas frontais precoces ou tardios.
\end{abstract}

Palavras-Chave: Regressão linear; Distribuição gama; Dias úmidos consecutivos; Estação Climatológica.

Abstract: The aim of this paper was to expose an overview of the rainfall measured at the Principal climatological station of Maringá, encompassing the period from 1980 to 2018. Four objectives outlined the research: i) obtaining descriptive statistics; ii) long-term trend evaluation; iii) probability distribution assessment of the daily rainfall, and iv) analysis of the consecutive wet days. Besides the general pattern of wet and dry periods, it was observed local maxima of rainfall in May and October. The long-term trends were evaluated by means of the linear regression, whereupon no significant trends were found. Nevertheless, by means of the mean test, it was verified that the recent years (2013 to 2018) were wetter than the remaining series (1980 to 2012). The Gamma distribution showed the best fit between the database and the theoretical distribution. In May, September and October the estimated daily volumes are higher than those estimated for other months. The period of highest number of consecutive wet days is between October and March. By the other side, the largest volumes per event happen in this period and in the following months: May and September. Although in the seasons of autumn and spring the monthly accumulated rainfall is lower than rainfall in the months of summer, in those seasons happen expressive daily rainfall, which extremes are larger than in the summer. This characteristic is related to the intensified action of lowpressure atmospheric systems, mainly troughs and early or late frontal systems.

Keywords: Linear regression; Gamma distribution; Consecutive wet days; Climatological station. 


\section{Introdução}

Na última década do século XX, a pauta das mudanças climáticas e do aquecimento global emergiu, não sendo uma novidade ao meio científico, mas introduziu o consenso à população de que a preocupação climática deve comparecer nas abordagens socioambientais. Comumente, as mudanças climáticas são atribuídas à causas naturais e humanas (BERGER; LABEYRIE, 1987), enquanto a variabilidade climática é expressa por oscilações naturais e periódicas observadas em séries históricas de dados, a partir da incidência de fenômenos atmosféricos, em diferentes escalas espaciais e temporais, conforme observado por Silva et al. (2015).

Sob a perspectiva científica, nas grandezas meso e microclimáticas, muitos trabalhos demonstraram pelos modelos e análises de tendências, a variabilidade climática em escalas mais finas, como a anual (BACK, 2001; CHAVES; CAVALCANTI, 2001; NATIVIDADE et al., 2017). Back (2001) ressaltou a dificuldade em estabelecer a existência de tendência devido à grande variabilidade natural dos dados meteorológicos. $\mathrm{O}$ autor utilizou análise estatística para identificar tendências anuais de temperatura e de precipitação para o estado de Santa Catarina. Natividade et al. (2017) concluíram que tanto para os índices de temperatura quanto para os índices de precipitação aplicados para Minas Gerais, a variabilidade interanual não teve uma simulação adequada pela média dos modelos.

A temperatura do ar e a precipitação são os elementos climáticos frequentemente avaliados nestes estudos, por comporem a magnitude de muitos fenômenos indutores de desastres naturais. Nesta pesquisa justifica-se o interesse pela análise da precipitação diária em Maringá-PR, pelo fato de a série histórica, de 1980 a 2018, apresentar, principalmente, a partir dos anos 2000, o aumento no total absoluto da precipitação, e por não haver trabalhos dessa natureza, com enfoque específico para a área.

Sob a perspectiva do senso comum, por Maringá ser um município de porte populacional médio, com cerca de 417.000 habitantes (IBGE, 2019a), qualquer evento chuvoso possui potencial para a formação de tempestades, consequentemente ventania e quedas de árvore. Não há o diagnóstico de um limiar de perigo representado pelas precipitações diárias, levando à conclusões truncadas de que as chuvas de verão são as grandes responsáveis pelos eventos extremos de precipitação, ou seja, aqueles cujo total ultrapassa a média esperada para a época do ano e que causam problemas à população.

O município localiza-se entre a transição das zonas climáticas intertropical e temperada, apresentando características térmicas, pluviais e higrométricas dos regimes tropical e subtropical (SILVEIRA, 2003). Grimm (2009) destacou que o norte da Região Sul do Brasil, no qual se situa Maringá, apresenta clima monçônico, sendo que a estação chuvosa inicia-se na primavera e termina no início do outono. De acordo com Sampaio et al. (2006), os resultados da distribuição gama aplicada à 22 séries de dados mensais de estações meteorológicas do Paraná, demonstraram aumento na quantidade de precipitação na direção oeste/litoral e norte/sul nos períodos mais chuvosos e secos, respectivamente. Pedron e Klosowski (2008) aplicaram a função de distribuição exponencial, utilizando 18 séries de dados diários de estações meteorológicas do Paraná, incluindo Maringá. Esses autores concluíram que a distribuição exponencial também é adequada para a descrição e estimativa da distribuição de frequências de precipitação, com intensidade diária superior a $10 \mathrm{~mm}$.

$\mathrm{Na}$ busca por um estudo de variabilidade local da precipitação, os objetivos foram: i) apresentar estatísticas descritivas da precipitação registrada na ECPM, nas seguintes escalas temporais: anual, mensal e diária; ii) avaliar tendências temporais da precipitação; iii) avaliar a distribuição de probabilidade da precipitação diária para fornecer os valores de precipitação respectivos a eventos extremos (grandes volumes de chuva diária), em escala mensal; iv) apresentar estatísticas descritivas dos dias consecutivos de chuvas.

\section{Materiais e métodos}

\section{1 Área de estudo e série histórica}

Maringá localiza-se na Mesorregião Norte Central Paranaense (Figura 1, IBGE, 1990, p. 105-106), possui clima de transição entre o tropical e o subtropical, com os seguintes dados médios para o período de análise: 1701,6 $\mathrm{mm}$ de pluviosidade, sendo janeiro e agosto, respectivamente, o mês mais chuvoso, concentrando $12,9 \%$ das chuvas, e mais seco da série, com 3,6\% das chuvas; janeiro e junho, os meses mais quente e mais frio, com $24,8^{\circ} \mathrm{C}$ e $18,2^{\circ} \mathrm{C}$, respectivamente, estando o mês mais quente $2,5^{\circ} \mathrm{C}$ acima da média e o mês mais frio, $4,1^{\circ} \mathrm{C}$ abaixo da média para o período. Destaca-se desvios-padrão médios significativos para ambos os elementos no inverno. 

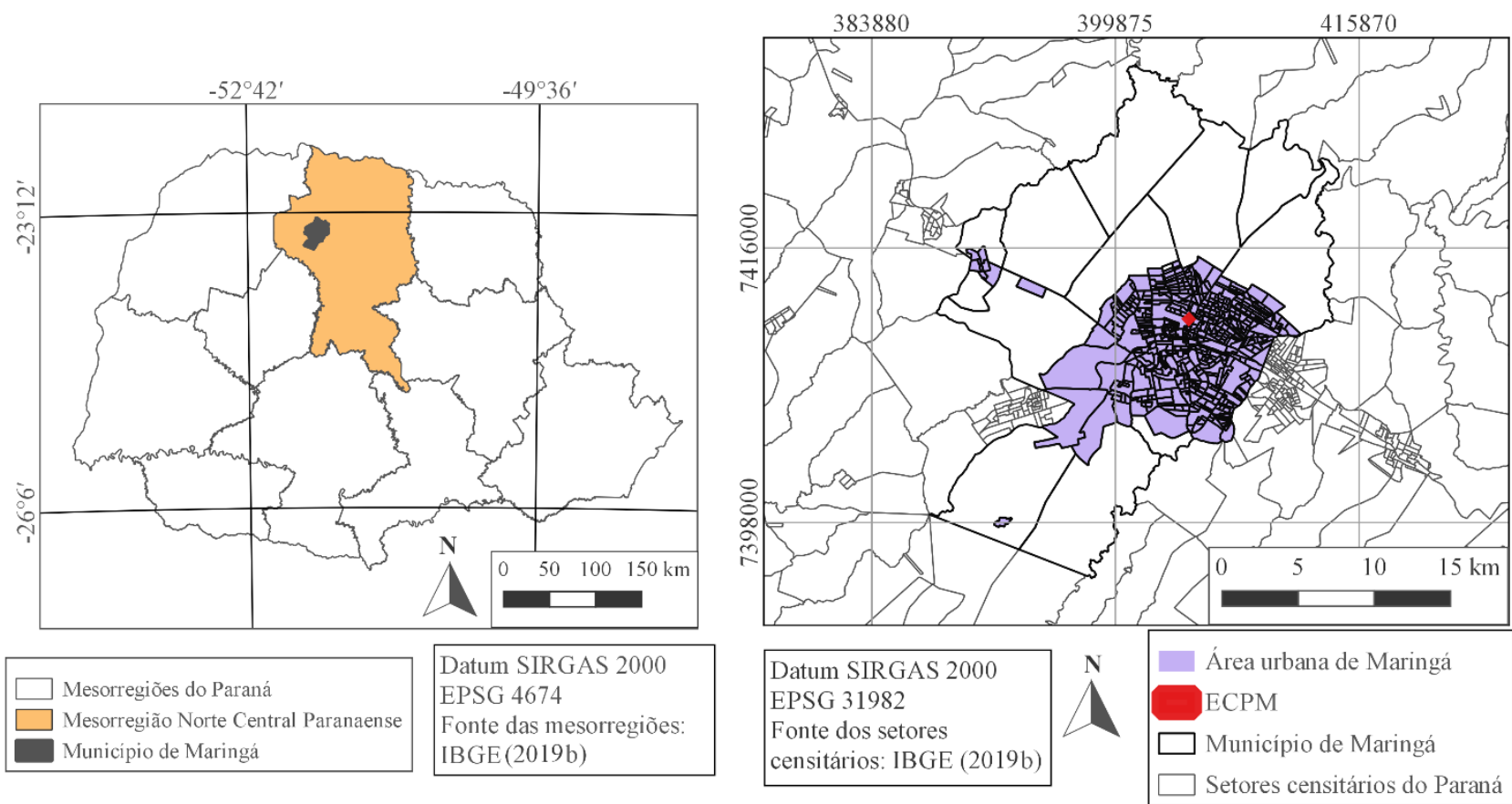

Figura 1: Localização do município de Maringá no contexto estadual e localização da ECPM na área urbana.

A fonte dos dados climáticos utilizados nesta pesquisa consistiu na estação do tipo convencional denominada Estação Climatológica Principal de Maringá (ECPM), com coordenadas 2324'19"S e $51^{\circ} 55^{\prime} 58^{\prime}$ 'W e altitude de $545 \mathrm{~m}$, instalada no interior do campus sede da Universidade Estadual de Maringá (UEM). Pertencente à rede de estações do Instituto Nacional de Meteorologia (INMET), com código 83767 na Organização Meteorológica Mundial (WMO), a ECPM possui uma série histórica superior ao período mínimo de uma normal climatológica. Uma característica interessante dessa série histórica é que ela não possui falhas para o período considerado. A base de dados proveniente dessa estação abrangeu os anos entre 1980 a 2018, seguidas as recomendações feitas pela WMO para trabalhos na escala diária, a saber: uso de períodos com dados completos (ausência de falhas na série histórica) e contabilização de dias de chuva apenas daqueles com precipitação acumulada igual ou superior a $1 \mathrm{~mm}$ (SILLMANN et al., 2013; INMET, 2018). Os valores de precipitação acumulada anual e mensal foram obtidos com a soma simples dos dias com precipitação diária $\geq 1 \mathrm{~mm}$. Os valores mensais médios ainda foram ponderados para permitir a comparação entre si da seguinte forma:

$$
P_{M p}=\frac{P_{M}}{N_{M}} \cdot 30
$$

Em que:

$P_{M p}=$ precipitação acumulada mensal ponderada (mm);

$P_{M}=$ precipitação acumulada mensal $(\mathrm{mm})$;

$N_{M}=$ número de dias em cada mês.

A Equação 1 foi aplicada considerando fevereiro com 28,25 dias (um dia adicional a cada ano bissexto) e meses com 30 dias de duração. Nesta pesquisa, utilizou-se a palavra precipitação como sinônimo de precipitação pluvial, equivalente a um valor mensurável, e a denominação chuva para o evento em si, sem a preocupação de quantifica-lo.

\subsection{Testes de tendência temporal e de médias}

Avaliou-se a possibilidade do uso da regressão linear para investigar a existência de tendência na série de valores totais anuais. O somatório da precipitação anual anula a sazonalidade intra-anual da precipitação, de 
forma que não é necessário corrigir tal efeito, como é realizado com uso do teste sazonal de Kendall, por exemplo. Por outro lado, por ser um teste paramétrico, a regressão linear possui algumas exigências a serem atendidas.

O teste de significância sobre o coeficiente angular (na regressão linear) assume que os resíduos possuem distribuição normal. Para um total de 39 anos, o teste de normalidade de Kolmogorov-Smirnov (com a correção de Lilliefors) foi aplicado, resultando em um valor-p maior do que 0,2. Portanto, assume-se que os resíduos possuem distribuição normal, de forma que a análise de regressão linear simples pôde ser utilizada para avaliação desta tendência.

Ainda com relação aos valores totais anuais, realizou-se um teste de médias $t$ (Student) entre dois períodos de tempo: 1980-2012 e 2013-2018. A seleção desses dois períodos para o teste, com intervalos temporais que não se equivalem, justifica-se pela distinção dos últimos anos da série (2013-2018) de altos valores anuais de precipitação, apresentando grande contraste com os valores anuais observados de 1980 a 2012. Assim, buscou-se avaliar se esses altos valores registrados nos anos mais recentes seguem a mesma média da série histórica. $\mathrm{O}$ teste $\mathrm{t}$ necessita da averiguação da homogeneidade das variâncias dos dois grupos, em que foi aplicado o teste $\mathrm{F}$.

\subsection{Modelagem probabilística da precipitação diária}

Eventos de frequência muito baixa constituem um importante objeto de estudo da climatologia, principalmente por suas sérias decorrências sociais e ambientais. No entanto, justamente por essa natureza temporal rara, nem sempre as normais climatológicas de 30 anos registram tais fenômenos, o que não significa que eles não possam ocorrer em uma determinada área. O período padrão da normal climatológica pode não ser suficiente para capturar toda a amplitude de variação dos elementos climáticos, em especial a precipitação (WMO, 2017). Embora as normais sejam utilizadas para o cálculo de estatísticas básicas como a média e o desvio-padrão, valores relativos a eventos extremos podem não ser tão confiáveis (WMO, 2017).

Ainda segundo a WMO (2017), o estudo de tais eventos extremos realiza-se a partir de duas formas: i) com uso de séries temporais suficientemente extensas; ou ii) por meio do ajuste de distribuições estatísticas baseadas nas normais climatológicas. Como exemplificado pela WMO (2017), séries históricas suficientemente longas podem constituir bases com mais de um século de existência, sem interrupções, o que não é usual na realidade brasileira. Portanto, muitas vezes é necessário recorrer à modelagem probabilística do fenômeno para que se estime seus valores em condições extremas.

A modelagem probabilística inicialmente parte da adoção de um modelo teórico de distribuição de probabilidades, em que, de forma geral, os modelos são divididos entre discretos e contínuos. Para este estudo, foram avaliadas algumas possibilidades de modelos contínuos de distribuição de probabilidades, devido à natureza da variável precipitação. As distribuições testadas foram as seguintes: weibull, exponencial, gama e lognormal. Distribuições como a normal e a t não foram testadas por apresentarem concentração de valores em torno da média, enquanto a precipitação diária possui maior frequência em valores baixos (próximos a 0), decrescendo para valores maiores.

A distribuição gama apresentou o melhor ajuste, como se observa nos gráficos Q-Q (quantil-quantil, Figura 2). De forma geral, as quatro distribuições ajustaram-se satisfatoriamente para os menores valores (até aproximadamente $30 \mathrm{~mm} / \mathrm{dia}$ ), mas as distribuições weibull, exponencial e lognormal não representaram bem as frequências dos maiores valores de precipitação, justamente o foco deste estudo.

A análise preliminar dos dados, representada na Figura 2, justificou a seleção da distribuição gama para representação das frequências de precipitação diária para a área de estudo. É importante mencionar que a Figura 2 apresenta um exemplo para o mês de fevereiro, em que tanto os valores anuais quanto os mensais tiveram resultados semelhantes. A distribuição gama é frequentemente utilizada para descrição probabilística da precipitação (SAMPAIO et al., 2006; PAIVA SOBRINHO et al., 2014; WMO, 2017); Paiva Sobrinho et $a l$. (2014) listam uma série de pesquisas que adotam essa distribuição, desde a década de 1950.

A máxima verossimilhança foi o método selecionado para estimativa dos parâmetros da distribuição gama, a saber, forma e escala. $O$ teste $\chi^{2}$ foi aplicado para verificação do ajuste entre a base de dados empírica (precipitação diária medida) e as distribuições teóricas anual e mensais. Foram obtidos valores-p maiores do que o nível de significância estabelecido (5\%) para todos os casos, o que permite o uso das distribuições ajustadas para descrição da precipitação diária para Maringá. Após a estimativa dos parâmetros da distribuição gama para as chuvas diárias (em cada mês), os resultados foram utilizados para estimativa de valores extremos de precipitação, considerando-se os seguintes limiares: $10 \%, 5 \%, 2,5 \%, 1 \%, 0,1 \%$ e $0,01 \%$. 

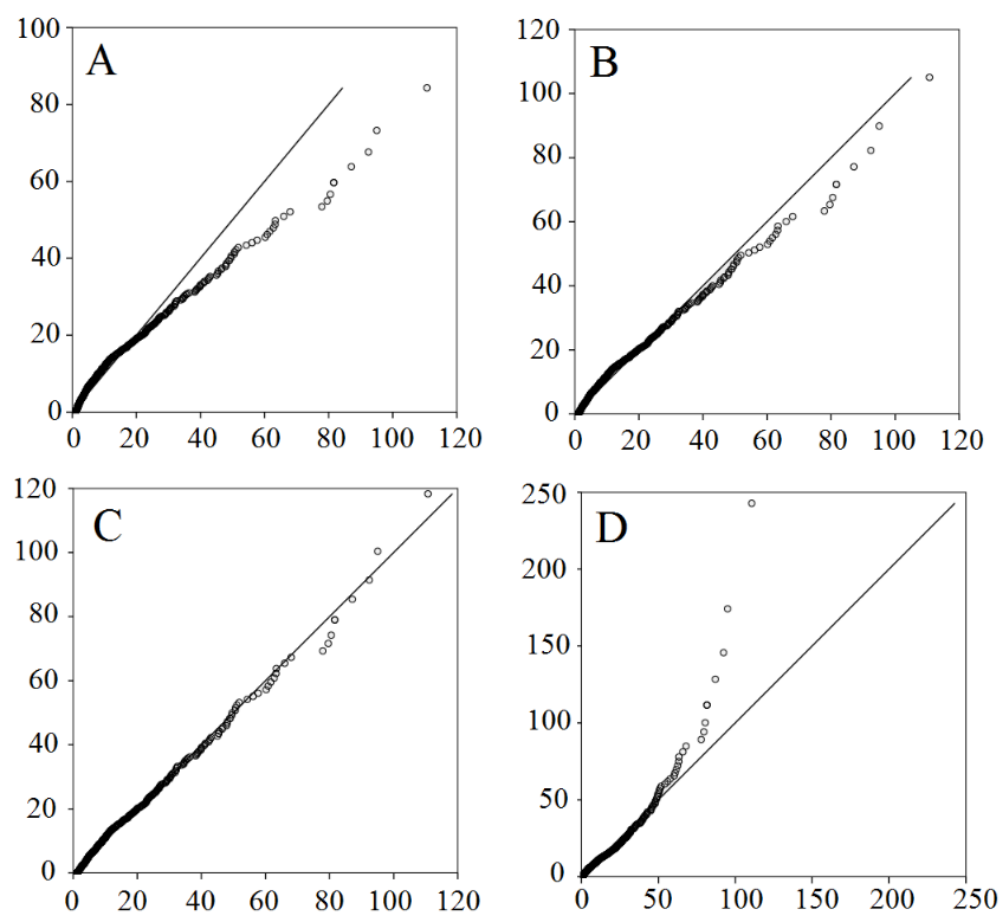

Figura 2: Gráficos quantil-quantil para a precipitação diária de fevereiro (1980-2018). A - weibull; B exponencial; C - gama; D - lognormal.

\subsection{Dias de chuva consecutivos}

A série histórica ininterrupta de dados diários permite uma avaliação consistente da dinâmica dos períodos chuvosos. Além da importância do volume total e do número de dias em que houve chuva, é também relevante a distribuição temporal de sua ocorrência. Uma sequência de dias de precipitação volumosa pode gerar condições mais propícias a alagamentos e escorregamentos de encostas, para citar apenas alguns problemas urbanos associados, do que se o mesmo volume fosse distribuído em um período de tempo maior, conforme se verifica em Tavares (2009).

O CWD (consecutive wet days) ou dias úmidos consecutivos é um importante índice de extremos climáticos que contabiliza o maior número de dias seguidos em um determinado ano em que houve precipitação $\geq 1 \mathrm{~mm}$ (SILLMANN et al., 2013). Este trabalho, no entanto, objetiva avaliar a distribuição, em escala intra-anual, dos dias úmidos consecutivos. Para isso, toda a série de dados foi transformada para uma sequência binária:

$$
B=\left\{\begin{array}{l}
0 \text { se } P<1 \\
1 \text { se } P \geq 1
\end{array}\right.
$$

Em que:

$\mathrm{P}=$ precipitação $(\mathrm{mm} / \mathrm{dia})$.

A partir dessa sequência binária obteve-se o valor absoluto da primeira derivada para $\Delta \mathrm{T}=1$ dia $(\mathrm{T}=$ tempo). Definindo-se como evento (E) um dia de chuva isolado, ou vários dias consecutivos de chuva; o número total de eventos (E) para um determinado período é dado por:

$$
E=\frac{\sum_{i=1}^{n}\left|B_{i+1}-B_{i}\right|}{2}
$$

Em que:

$\mathrm{B}_{\mathrm{i}}=$ variável binária que indica existência de precipitação em um dia;

$\mathrm{B}_{\mathrm{i}+1}=$ variável binária que indica existência de precipitação no dia posterior a $\mathrm{B}_{\mathrm{i}}$;

$\mathrm{n}=$ número de dias avaliado. 
A variável binária (Equação 2) também foi utilizada para obtenção de dias com precipitação (C) para um determinado período:

$$
C=\sum_{i=1}^{n} B_{i}
$$

Em que:

$\mathrm{C}=$ Dias com precipitação $\geq 1 \mathrm{~mm}$.

A partir das variáveis E e C, obteve-se a duração dos eventos:

$$
D=\frac{C}{E}
$$

Em que:

D = Duração média dos eventos (dias);

A última variável relacionada aos eventos de chuva em dias consecutivos se refere ao volume total em cada evento:

$$
A=\frac{\sum_{i=1}^{n} P_{i}}{E}
$$

Em que:

$\mathrm{A}=$ Acumulado de chuva por evento $(\mathrm{mm} / \mathrm{E})$;

O somatório da variável $\mathrm{P}$ (precipitação, em mm/dia - Equação 6) ocorreu apenas para dias com $\mathrm{P} \geq$ $1 \mathrm{~mm}$. As variáveis descritas nesse tópico foram obtidas para as médias mensais de todo o período avaliado (1980-2018).

\section{Resultados e discussões}

\subsection{Valores anuais de precipitação}

Para o período compreendido entre 1980 a 2018, a precipitação média anual calculada correspondeu a $1706,08 \mathrm{~mm}$. A regressão linear aplicada para o período mostrou uma leve tendência de aumento, mas que não foi significativa, com valor-p de 0,14 (Figura 3, em azul). Outra regressão linear foi aplicada para o período entre 1980 a 2012 (Figura 3, em vermelho), cuja tendência foi de leve diminuição, mas também não significativa. Portanto, a atual base de dados não permite afirmar que há alguma tendência linear constante na chuva registrada na ECPM.

A diferença observada entre as duas retas obtidas para os dois períodos avaliados (Figura 3) deve-se ao fato de que entre os anos de 2013 a 2018, houve registros de altos valores de precipitação anual. De fato, a média para o primeiro período (1980-2012) é de $1638,5 \mathrm{~mm}( \pm 244 \mathrm{~mm})$ e para o segundo período (2013$2018)$ é de $2077,7 \mathrm{~mm}$ ( $\pm 323 \mathrm{~mm})$. O teste $\mathrm{F}$ apontou que não há diferença significativa entre as variâncias desses dois grupos, enquanto pelo teste t verificou-se diferença significativa entre as médias para $\alpha=5 \%$. $\mathrm{O}$ valor $t$ observado foi de $-3,85$ (valor-p: 0,000447), enquanto o tabelado foi de $-2,02$. Portanto, apesar da baixa quantidade de anos para o segundo período (apenas seis anos), sua média difere significativamente em relação ao primeiro período. Isso se deve principalmente ao ano de 2015 , cuja precipitação registrada foi muito superior a um desvio padrão acima da média (Figura 4). 


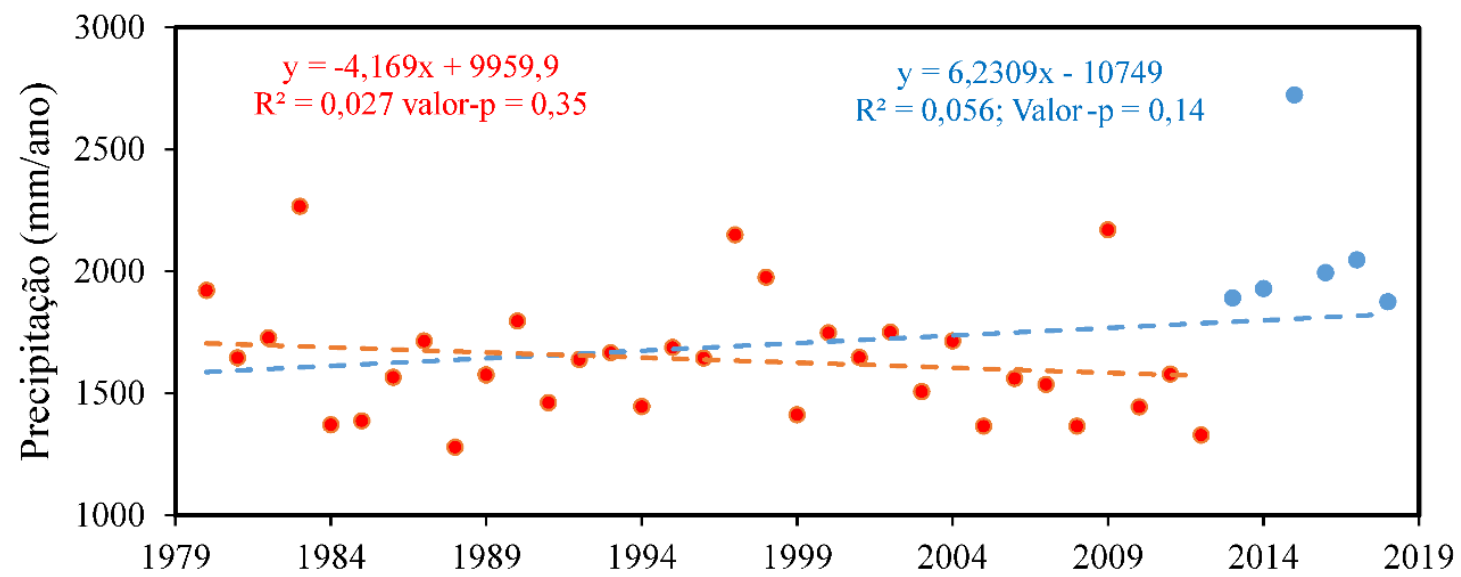

Figura 3: Tendências ajustadas por regressão linear simples para dois períodos: 1980-2012 (vermelho) e 1980-2018 (azul) para os valores de precipitação anual registrados na ECPM.

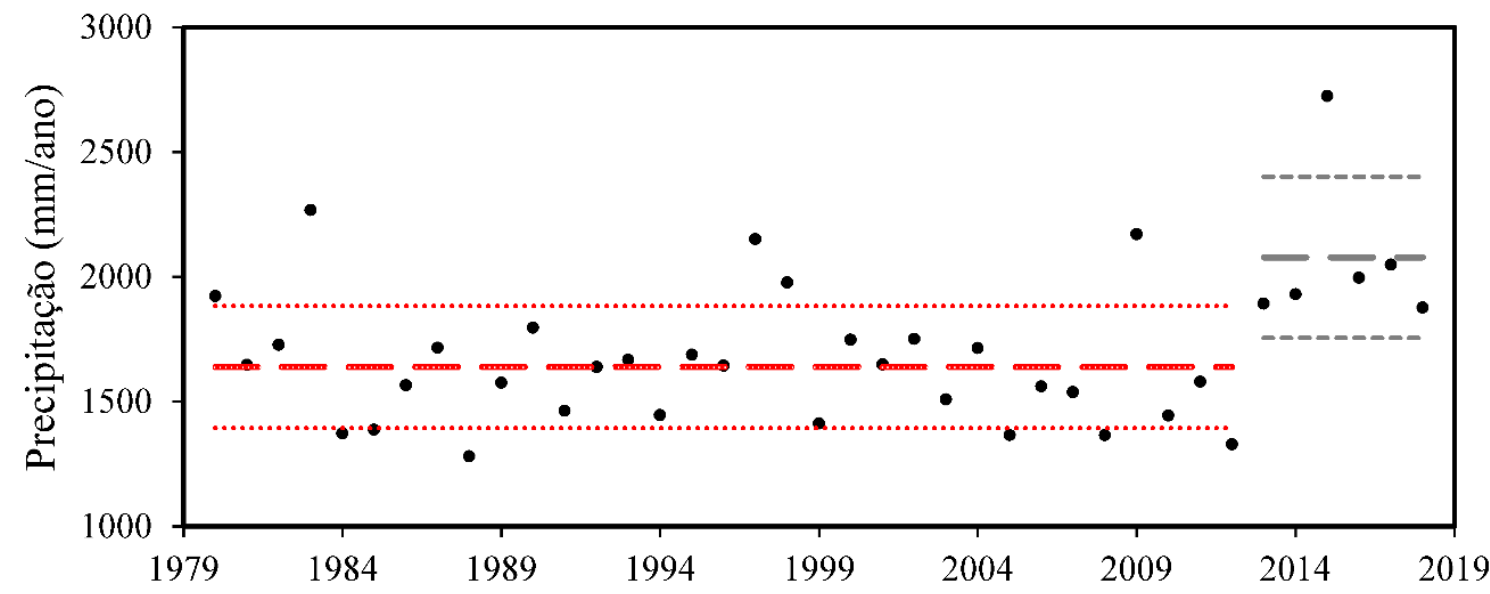

Figura 4: Médias e desvio padrão para dois períodos: 1980-2012 (vermelho) e 2013-2018 (cinza) para os valores de precipitação anual registrados na ECPM.

Chama-se atenção para o fato de que, apesar de os seis anos mais recentes terem apresentado uma média diferente do restante da série, não se pode afirmar que o padrão das chuvas realmente se alterou. Fenômenos globais, ou mesmo regionais, como as variações nas temperaturas de superfície dos oceanos Pacífico e Atlântico, podem ter influenciado o aumento das chuvas nesse período, efeito observado no Paraná e descrito por Cavalcanti (1996). Cita-se o episódio El Niño de 2015/2016, no qual a anomalia da temperatura da superfície do mar (TSM) alcançou $+2,64^{\circ} \mathrm{C}$ no trimestre novembro-dezembro-janeiro, a maior desde 1950 (NOAA, 2019). Se, ao contrário, uma mudança estrutural tenha ocorrido no padrão regional de distribuição das chuvas, é necessário avaliar a continuidade da série temporal, a partir de 2019, para confirmação.

\subsection{Valores mensais de precipitação}

As médias mensais das precipitações em Maringá (Figura 5) mostram que os meses com os maiores valores são dezembro, janeiro e fevereiro (verão), período de ingresso frequente dos sistemas tropicais úmidos, enquanto os meses com menores valores são principalmente julho e agosto, com entrada intensificada dos sistemas extratropicais - a frente fria e a massa de ar polar.

O padrão de máximos (verão) e mínimos (inverno) de precipitação é bem descrito na bibliografia (GRIMM et al., 1998; GRIMM, 2009). Por outro lado, as médias mensais também apresentam dois máximos locais, em outubro (primavera) e maio (outono). Em ambas as estações de transição podem ocorrer os Complexos Convectivos de Mesoescala (CCM), trazendo chuva à região (GRIMM, 2009, p. 271). 


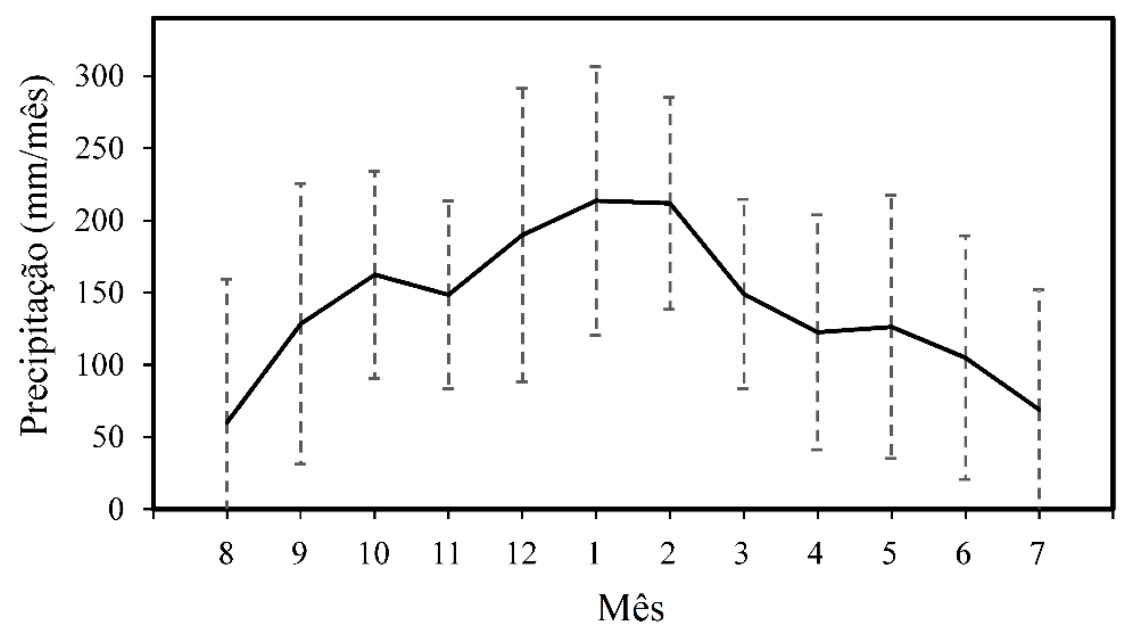

Figura 5: Médias e desvio-padrão para os valores de precipitação mensal registrados na ECPM. Médias calculadas considerando meses de 30 dias (ver Equação 1).

\subsection{Valores diários de precipitação}

Nos 39 anos completos de série histórica houve o registro de 3840 dias com precipitação $\geq 1 \mathrm{~mm}$, sendo que esta extensa base foi representada por meio de box plot (Figura 6). Os box plot mostram uma distribuição assimétrica das chuvas diárias, com forte concentração em valores baixos e maior dispersão para valores maiores (em conformidade com a distribuição gama).

Os box plot também mostram que os valores diários de cada mês não possuem as mesmas estatísticas descritivas e que essas diferenças não têm o mesmo padrão das médias mensais (Figura 5). Portanto, há diferenças de dinâmica das chuvas diárias entre os meses, mas não há uma tendência de que nos meses mais chuvosos as chuvas diárias sejam mais intensas do que nos meses mais secos. Tanto os mínimos quanto os limites inferiores dos segundos quartis são semelhantes em comparação entre os doze meses. Por outro lado, as medianas e os limites superiores do terceiro quartil já apresentam diferenças notáveis, enquanto os limites superiores do intervalo sem outliers e a distribuição de outliers e extremos são ainda mais evidentes.

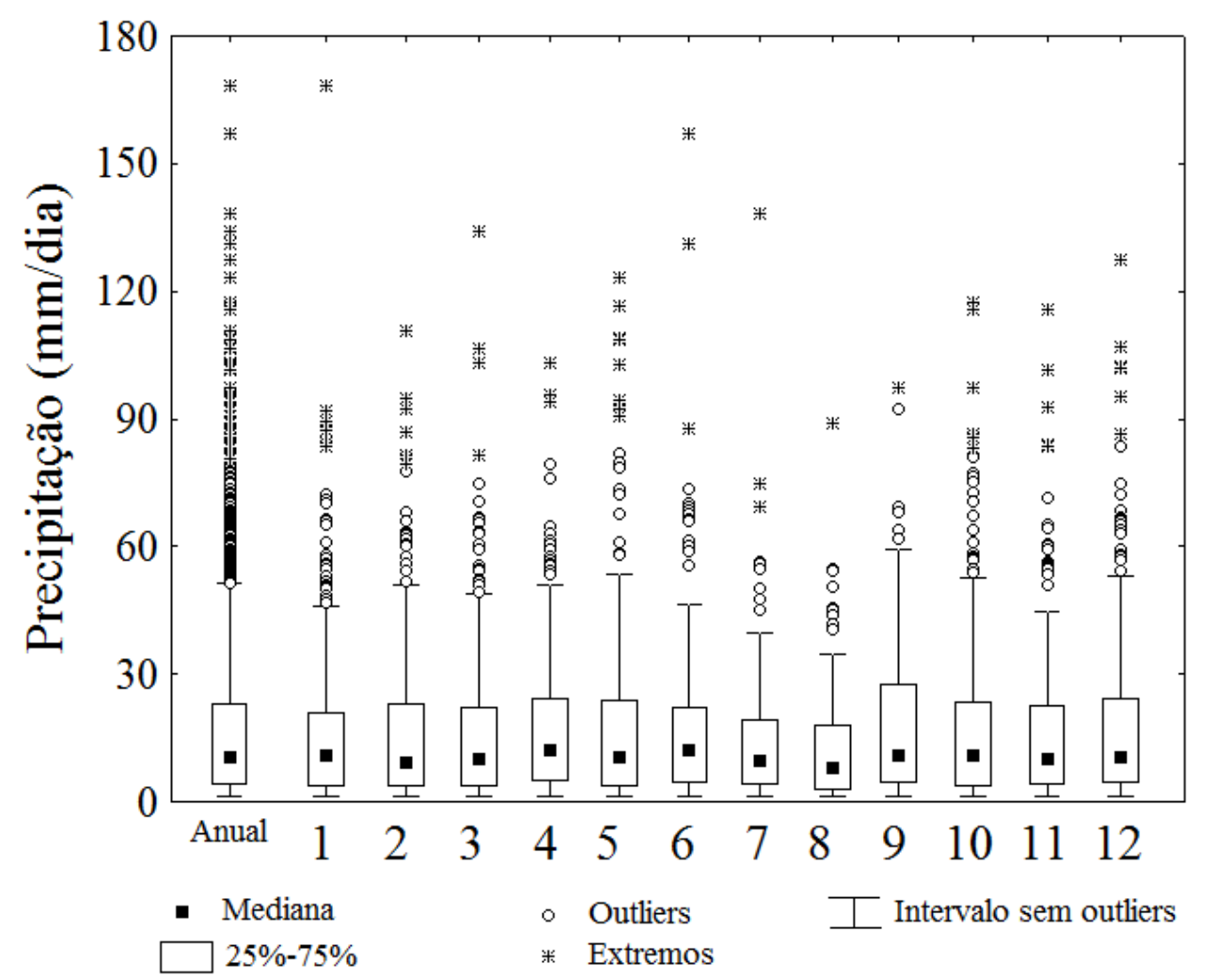

Figura 6: Médias e desvio padrão para os valores de precipitação mensal registrados na ECPM. Médias calculadas considerando meses de 30 dias (ver Equação 1). 


\subsubsection{Distribuição gama e probabilidade de valores extremos}

Os box plot também mostram que os valores diários não possuem a mesma forma de distribuição, embora todos os meses e os valores anuais possam ser aproximados para uma distribuição gama. Portanto, os parâmetros de forma $(\gamma)$ e escala $(\beta)$ foram ajustados para cada conjunto (Tabela 1). Os ajustes entre os valores diários e as distribuições gama estimadas (Tabela 1) podem ser avaliados por meio das curvas teóricas sobrepostas aos histogramas mensais (Figura 7).

Tabela 1: Parâmetros estimados da distribuição gama para os conjuntos mensais e anual de precipitações diárias registradas na ECPM.

\begin{tabular}{cccccccc}
\hline Mês & Jan. & Fev. & Mar. & Abr. & Maio & Jun. & Jul. \\
\hline$\gamma$ & 1,047 & 1,037 & 1,015 & 1,125 & 0,930 & 1,060 & 1,137 \\
$\beta$ & 15,441 & 15,305 & 15,882 & 16,051 & 19,998 & 16,507 & 13,067 \\
\hline Mês & Ago. & Set. & Out. & Nov. & Dez. & Anual & \\
\hline$\gamma$ & 1,080 & 1,063 & 0,965 & 1,089 & 1,059 & 1,037 & \\
$\beta$ & 11,948 & 17,036 & 18,379 & 14,839 & 16,668 & 16,143 & \\
\hline
\end{tabular}

As distribuições gama com os parâmetros descritos na Tabela 1 foram então utilizadas para estimativa de valores de precipitação em alguns limiares pré-determinados (Tabela 2). Os valores de cada célula da Tabela 2 mostram o total de precipitação que é igualado ou excedido para determinado nível de probabilidade. Por exemplo, considerando o mês de janeiro, $90 \%$ das precipitações diárias com registro $\geq$ $1 \mathrm{~mm}$ constituem acumulados diários de até $38,2 \mathrm{~mm}$. Ou seja, esse limiar é ultrapassado em apenas $10 \%$ das precipitações modeladas nessas condições. Considerando o mesmo valor de probabilidade, mas no mês de maio, por exemplo, as precipitações que constituem o grupo de $10 \%$ mais volumosas é $\geq$ do que 43,62 mm.
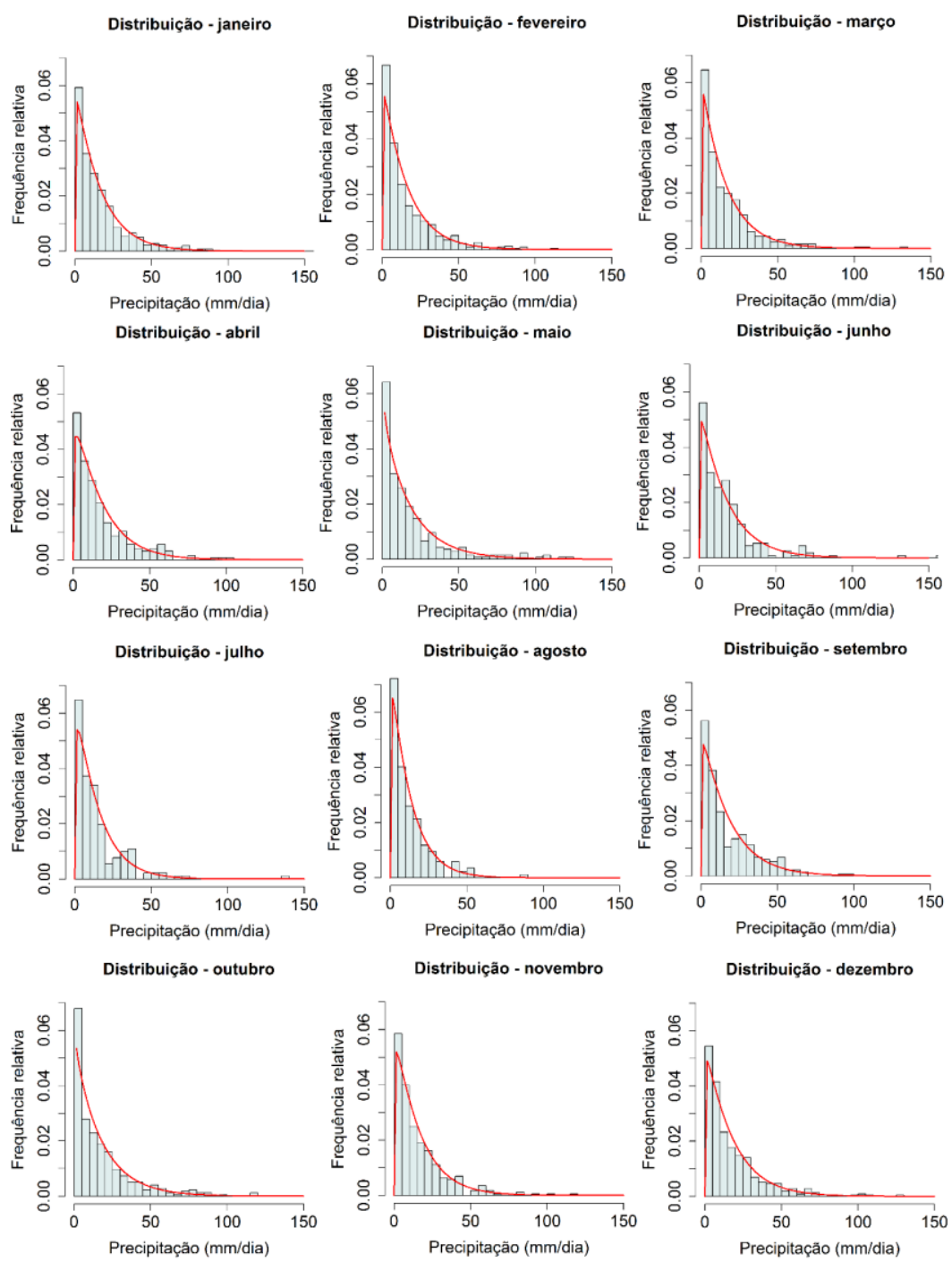

Figura 7: Histograma e distribuição gama ajustada para os valores mensais de precipitação diária registrados na ECPM. As curvas em vermelho possuem distribuição gama com parâmetros descritos na Tabela 1. 
Enquanto a Tabela 2 apresenta os valores de modo preciso, a Figura 8 constitui uma representação que permite uma compreensão mais simplificada da dinâmica das chuvas diárias registradas na ECPM no decorrer do ano. A cor verde-escura na Figura 8 apresenta o limite de 90\% das chuvas diárias, enquanto a cor verde-clara indica a faixa situada entre 90 e $95 \%$ das chuvas e, assim, consecutivamente. Valores menos frequentes do que em $0,01 \%$ das chuvas diárias são aqueles que estão acima do limite superior da faixa em vermelho.

Tabela 2: Precipitação (mm/dia) estimada para a ECPM por meio da distribuição gama para diversos níveis de probabilidade.

\begin{tabular}{cccccccccccccc}
\hline $\begin{array}{c}\text { P } \geq \mathbf{X} \\
(\boldsymbol{\%})\end{array}$ & Anual & Jan. & Fev. & Mar. & Abr. & Maio & Jun. & Jul. & Ago. & Set. & Out. & Nov. & Dez. \\
\hline 10 & 38,2 & 36,81 & 36,22 & 36,99 & 40,41 & 43,62 & 39,73 & 33,15 & 29,16 & 41,1 & 41,22 & 36,44 & 40,09 \\
5 & 49,51 & 47,66 & 46,94 & 48,05 & 51,93 & 57,2 & 51,37 & 42,56 & 37,63 & 53,12 & 53,83 & 46,99 & 51,84 \\
2,5 & 60,8 & 58,48 & 57,64 & 59,09 & 63,38 & 70,82 & 62,98 & 51,91 & 46,07 & 65,11 & 66,47 & 57,49 & 63,56 \\
1 & 75,71 & 72,76 & 71,77 & 73,69 & 78,45 & 88,89 & 78,29 & 64,2 & 57,19 & 80,92 & 83,19 & 71,32 & 79,01 \\
0,1 & 113,09 & 108,57 & 107,21 & 110,35 & 116,1 & 134,44 & 116,65 & 94,9 & 85,03 & 120,52 & 125,29 & 105,95 & 117,74 \\
0,01 & 150,41 & 144,32 & 142,6 & 146,98 & 153,5 & 180,13 & 154,91 & 125,44 & 112,79 & 160,03 & 167,45 & 140,45 & 156,37 \\
\hline
\end{tabular}

As chuvas diárias mais frequentes (até $90 \%$ ) tendem a ser similares no decorrer do ano (em verde na Figura 8), embora é possível notar dois momentos em que são levemente superiores - o primeiro em maio e o outro em setembro e outubro. No entanto, quanto mais raras se tornam as chuvas diárias, mais esses picos ficam proeminentes. Ou seja, considerando um dia de precipitação $\geq 1 \mathrm{~mm}$ para cada mês do ano, os eventos mais extremos de precipitação tendem a ocorrer com maior probabilidade principalmente nos meses de maio, setembro e outubro.

É importante mencionar que as probabilidades não apresentam descontinuidades aleatórias, havendo uma continuidade temporal de seus valores. Iniciando-se a análise em janeiro, por exemplo, observa-se que os valores aumentam a partir de março, têm um pico em maio e decrescem até agosto, quando voltam a aumentar até outubro e diminuir novamente em novembro. Também há um máximo local em dezembro, mas inferior aos máximos supracitados.

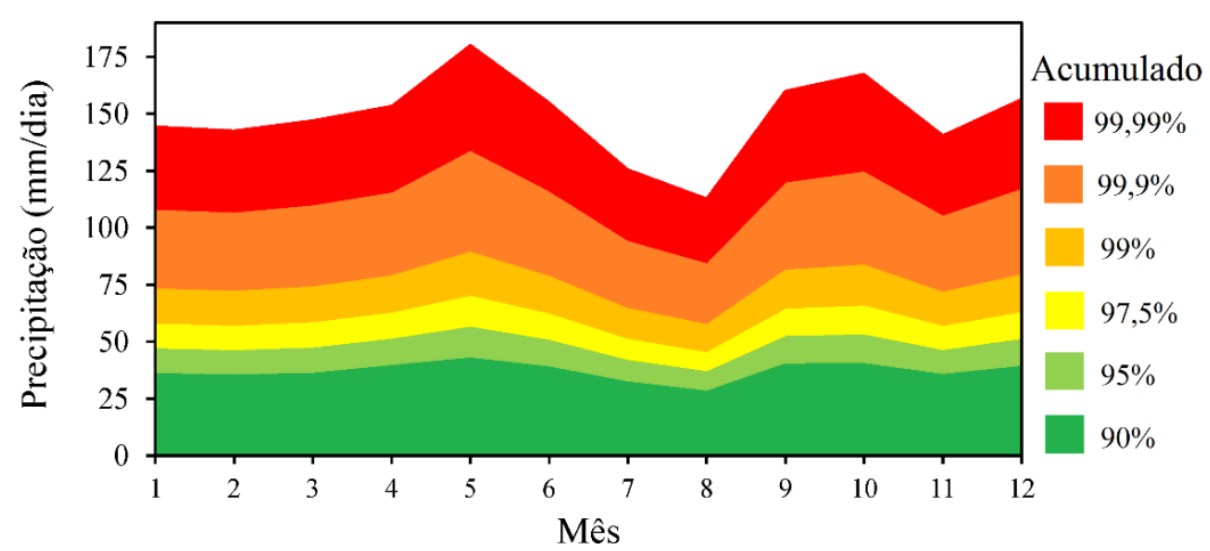

Figura 8: Faixas de valores de precipitação diária para diversos níveis de frequência acumulada. Para consultar os valores absolutos de probabilidade, vide Tabela 2.

Apesar de o volume acumulado mensal ser superior nos meses de dezembro, janeiro e fevereiro (Figura 5), as chuvas diárias tendem a ser mais volumosas nas estações de transição (outono e primavera). Tal resultado parece ser contraditório, a primeiro momento, mas deve-se ao fato de que nos meses com maiores volumes acumulados, o número de dias em que há precipitação $\geq 1 \mathrm{~mm}$ é superior, resultando, portanto, em um maior volume total. Um maior número de dias de chuva também faz com que altos valores de precipitação (de baixa probabilidade de ocorrência) sejam atingidos mais vezes.

Como o número de dias em que há precipitação não é o mesmo em todos os meses, as frequências descritas na Tabela 2 e na Figura 8 não podem ser diretamente comparadas. Tais informações podem ser compreendidas a partir do seguinte exemplo: supondo-se duas previsões, para o dia seguinte, de chuva 
registrável ( $\geq 1 \mathrm{~mm}$ ) em dois momentos, um em janeiro (verão) e outro em maio (outono), a probabilidade de haver um volume de chuva mais expressivo, é maior no mês de maio.

Esses resultados podem ser aplicados, pois a partir da identificação dos momentos do ano mais sujeitos aos eventos extremos, o poder público pode absorver esta informação para a prevenção e a mitigação de desastres. Principalmente, os de origem em perigos hidrometeorológicos (hydrometeoological hazard, UNISDR, 2009), suas consequências, assim como acidentes que não se enquadram no conceito de desastre da UNISDR (2009), mas que interrompem o equilíbrio dinâmico dos espaços ocupados.

\subsubsection{Eventos: dias úmidos consecutivos}

O número de eventos (E), duração dos eventos (D), total de dias com precipitação $\geq 1 \mathrm{~mm}(\mathrm{C})$ e o volume de precipitação por evento (A) foram obtidos para médias mensais (Tabela 3). A Figura 9 simplifica a visualização desses dados. O número de eventos não segue o mesmo padrão dos totais mensais (Figura 5), em que não é observado um máximo local em maio. Além de dezembro e janeiro, são observados valores mais altos para março e outubro. Isso mostra que, apesar dos relativos maiores volumes totais em maio, há poucos eventos de dias consecutivos de chuva quando comparados com outros meses. Portanto, os eventos em maio tendem a ser mais volumosos em termos de total acumulado por evento (variável A, Tabela 3 e Figura 9). Vale ressaltar que em abril e junho (outono) essa interpretação também é válida, mas nesses meses os acumulados por evento são um pouco inferiores.

A variável D mostra que não há uma variação absoluta expressiva da duração dos eventos no decorrer do ano. No entanto, em termos relativos, o mês com maior valor (2,62 dias em janeiro) é aproximadamente 50\% maior do que o mês com menor valor (1,74 dias em junho). No entanto, conciliado com a maior duração dos eventos, nos meses com maiores totais também há um maior número de eventos (variável E).

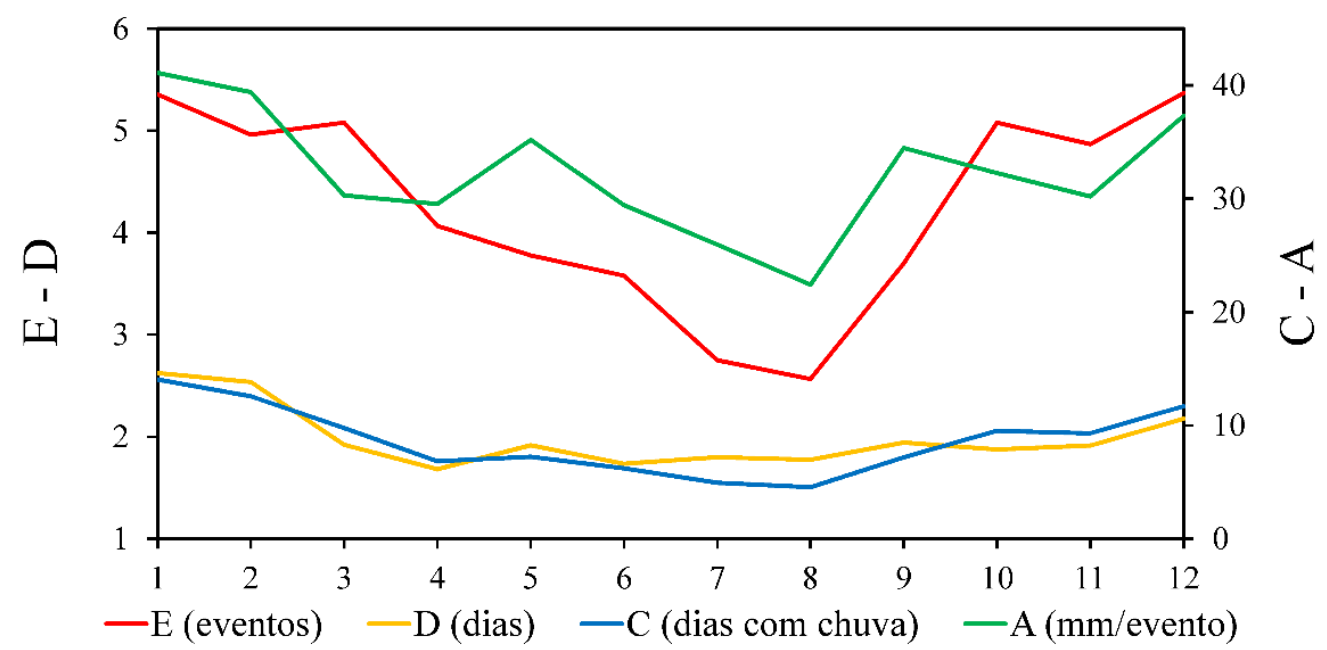

Figura 9: Valores mensais médios das seguintes variáveis: $\mathrm{E}$ - número de eventos; D - duração dos eventos (dias); $\mathrm{C}$ - dias com precipitação $\geq 1 \mathrm{~mm}$; A - acumulado de precipitação em cada evento (mm/evento). Para consultar os valores absolutos dessas quatro variáveis, vide Tabela 3.

Tabela 3: Médias mensais do número de eventos, duração, total de dias com chuva e volume por evento para a ECPM.

\begin{tabular}{lrrrrrrrrrrrr}
\hline Variável & Jan. & Fev. & Mar. & Abr. & Maio & Jun. & Jul. & Ago. & Set. & Out. & Nov. & Dez. \\
\hline E (eventos) & 5,36 & 4,96 & 5,08 & 4,07 & 3,78 & 3,58 & 2,75 & 2,57 & 3,70 & 5,08 & 4,87 & 5,37 \\
D (duração) & 2,62 & 2,54 & 1,92 & 1,68 & 1,92 & 1,74 & 1,80 & 1,77 & 1,94 & 1,88 & 1,91 & 2,18 \\
C (dias úmidos) & 14,05 & 12,58 & 9,76 & 6,84 & 7,24 & 6,21 & 4,95 & 4,55 & 7,18 & 9,53 & 9,32 & 11,68 \\
A (mm/evento) & 41,10 & 39,39 & 30,29 & 29,53 & 35,18 & 29,42 & 25,95 & 22,42 & 34,49 & 32,25 & 30,19 & 37,30 \\
\hline
\end{tabular}

Os máximos locais dos valores acumulados de precipitação por evento (A) nos meses de maio (outono) e em setembro e outubro (primavera), muitas vezes ocorrem a partir de atuações individualizadas de sistemas meteorológicos ou de combinações entre eles, que tendem a alcançar volumes de precipitação acima do normal. A formação destes eventos significativos também se explica pelo tamanho do sistema influenciador e pela amplitude de sua baixa pressão. Observa-se estas condições sinóticas de instabilidade e de precipitação 
geradas por sistemas de baixa pressão nos dias 08 e 09/09/2015 (Figura 10). Nestes episódios abrangidos por um período maior, de 06 a 11/09/2015, a precipitação total registrada em cinco dias alcançou 116,6 mm, sendo que os dias 08 e 10/09/2015 concentraram grande parte deste total, com 52,3 mm e 54,8 mm, respectivamente. Como se observa na carta sinótica do dia 08/09/2015, o Paraná estava sob influência de um extenso cavado, com dois núcleos mais frios visualizados na mesma faixa latitudinal na imagem de satélite. A instabilidade observada no dia 10/09/2015 é melhor interpretada pela observação das condições sinóticas no dia anterior. Como se nota na Figura 10, no dia 09/09/2015, a presença de cavado e de sistemas frontais influenciando a região e estados de fronteira com o Paraná, gerou nebulosidade e o possível contraste mais acentuado de temperatura entre a superfície e o topo das nuvens, causando precipitação durante e após a passagem dos sistemas atmosféricos.
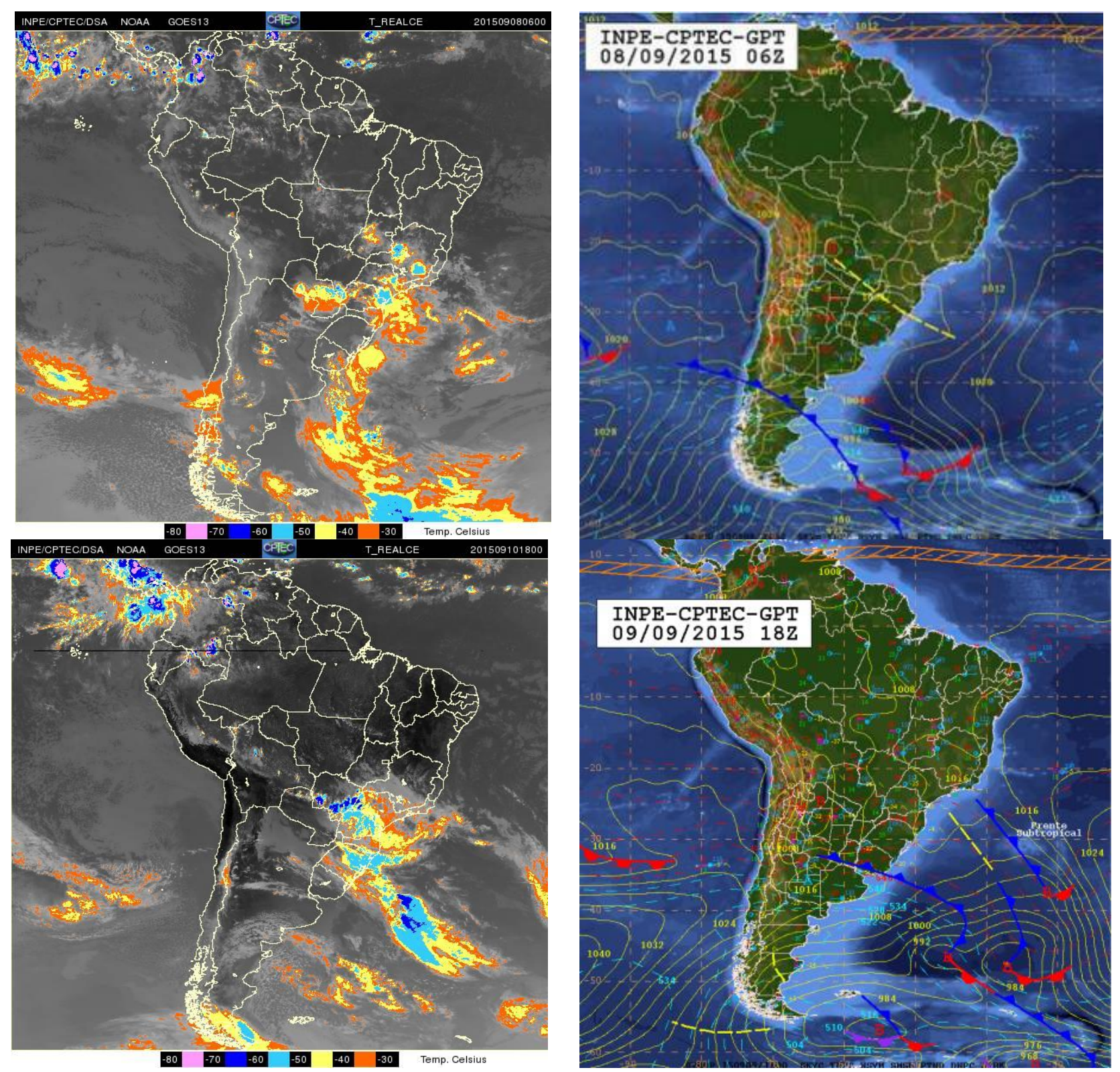

Figura 10: Imagens do satélite GÓES-13, canal da temperatura realçada (à esquerda) e cartas sinóticas (à direita) dos dias 08 e 09/09/2015, respectivamente às $3 \mathrm{~h}$ e às $15 \mathrm{~h}$, pelo horário oficial do Brasil. Este período de chuvas de 06/09/2015 a 11/09/2015 teve a influência de sistemas frontais e de cavados, alternando entre a atuação isolada ou combinada dos sistemas atmosféricos. Fonte: CPTEC/INPE (2019a, 2019b).

Diferentemente da frente fria, no cavado as linhas de baixa pressão não se fecham, e apresentam uma ondulação para o lado das altas pressões (CPTEC/INPE, 2019c). Dependendo de sua magnitude, da convergência de umidade e da pressão, pode-se formar linhas de instabilidade sobre o local de passagem, causando chuva pelas áreas sob sua influência. Cita-se o período de 18 a 21/05/2017, com registro de 211,8 $\mathrm{mm}$ de precipitação, ultrapassando em $85,2 \mathrm{~mm}$ a média do mês de maio. Neste período, houve a formação diária de cavados, acentuando a nebulosidade e a instabilidade atmosférica sobre a área. Na Figura 11 
destaca-se o dia 21/05/2017, com um cavado na fronteira entre os estados do Paraná e de São Paulo e ainda a presença de nuvens com topos frios nesta mesma extensão, com precipitação registrada no valor de 72,2 mm.

Um exemplo de sistema frontal condicionando valores mais elevados de precipitação sobre Maringá pode ser observado no dia 03/10/2015, com registro de 83,2mm de precipitação. Esses picos significativos de chuva em estações de transição, exemplificados nas Figuras $\mathbf{1 0}$ e 11, podem se associar tanto à atuação mais precoce ou mais tardia de sistemas frontológicos intensos, como advir de cavados, individualizados ou em conjunto sobre a área, com outros cavados ou com sistemas frontais. Outra possível fonte dos eventos significativos de precipitação na área são os sistemas depressionários do Chaco e, mais raramente, os Complexos Convectivos de Mesoescala. Sob a condição da atmosfera inferior mais aquecida, assim como de águas oceânicas com temperatura de superfície acima da média, no que se refere à precipitação, os volumes podem ser intensificados.
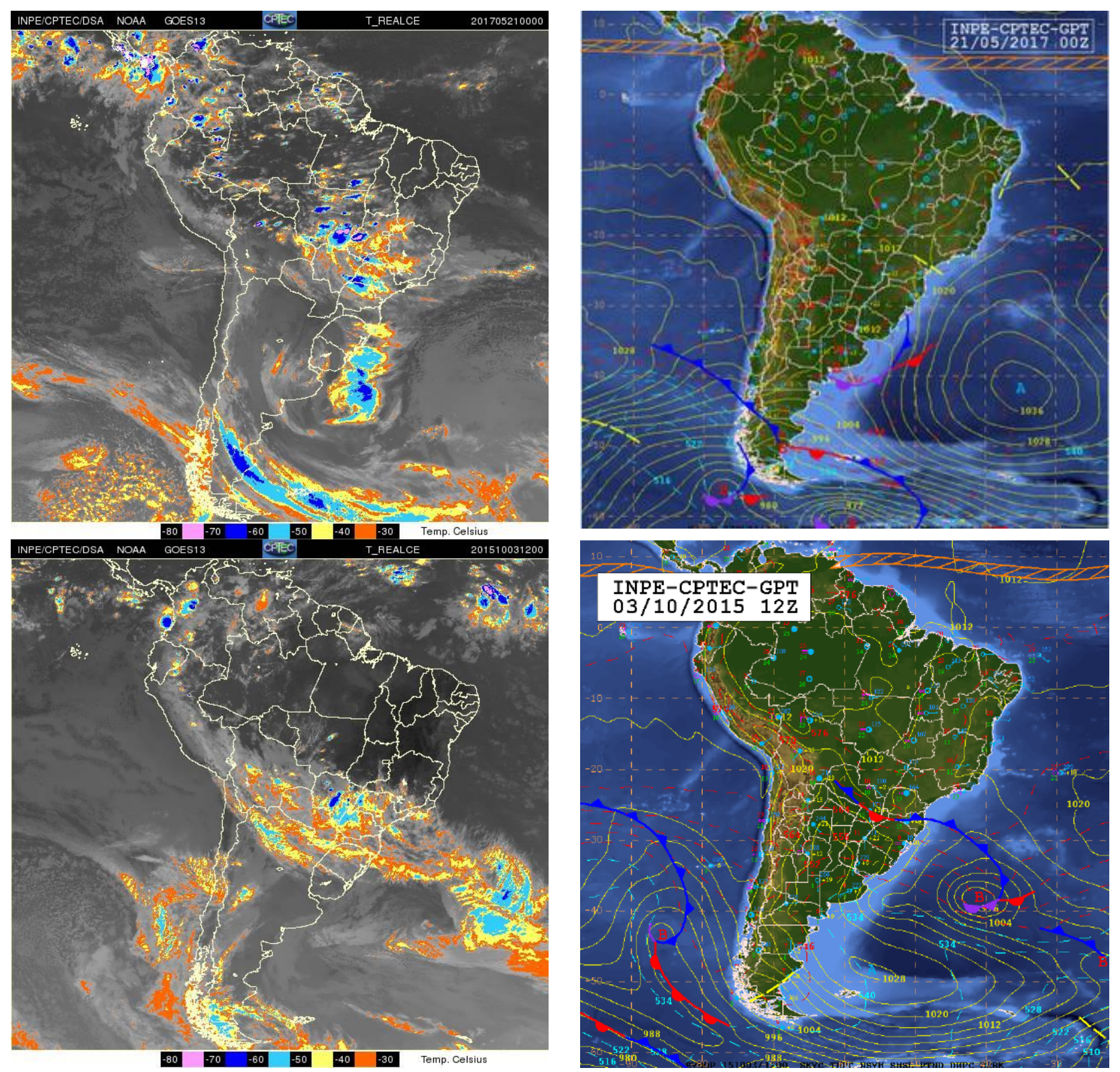

Figura 11: Imagens do satélite GÓES-13, canal da temperatura realçada (à esquerda) e cartas sinóticas (à direita) dos dias 20/05/2017 e 02/10/2015, respectivamente às $21 \mathrm{~h}$ e às $9 \mathrm{~h}$, pelo horário oficial do Brasil. Observar que a precipitação do dia seguinte à 02/10/2015 foi a referência utilizada no texto para exemplificar um evento expressivo de precipitação. Fonte: CPTEC/INPE (2019a, 2019b)

\section{Conclusões}

Este trabalho permitiu as seguintes conclusões: 
- Em relação às tendências avaliadas sobre os totais anuais: não foram observadas tendências lineares significativas para o período entre 1980 a 2018. No entanto, entre 2013 a 2018 verificou-se precipitação significativamente superior em relação ao restante da série. Todavia, não se pode afirmar sobre alguma mudança estrutural no padrão de chuvas na região, principalmente porque os maiores valores desse período podem estar relacionados com o El Niño de 2015/2016;

- Em relação às médias mensais de precipitação: observou-se o padrão já conhecido para a área de estudo, de chuvas mais volumosas nos meses de dezembro, janeiro e fevereiro e menores nos meses de julho e agosto. Além desse padrão geral, também há máximos locais em maio e outubro, relacionados com as estações de transição (outono e primavera). Apesar desse padrão apresentado pelas médias, o desviopadrão em todos os meses é alto, o que mostra a grande variabilidade interanual da precipitação em Maringá-PR;

- Em relação à modelagem probabilística das chuvas diárias: a distribuição gama aderiu-se satisfatoriamente aos dados observados, em concordância com outros trabalhos (mencionados na introdução) que utilizam essa distribuição para descrição de chuvas. Eventos relativamente mais frequentes (até 90\% das chuvas diárias) são muito semelhantes no decorrer do ano. No entanto, para eventos extremos de precipitação diária, com probabilidade de ocorrência $\leq 0,1 \%$, observou-se que em maio, setembro e outubro, os volumes estimados são superiores aos observados no restante do ano. Isso está relacionado à atuação intensificada de sistemas atmosféricos de baixa pressão, principalmente cavados e sistemas frontais precoces ou tardios;

- Em relação aos eventos de dias consecutivos com chuva: o período com maior número de eventos ocorre entre outubro e março, mesmo intervalo em que incidem os maiores acumulados totais mensais. Por outro lado, os maiores valores de precipitação por evento acontecem nesses meses e nas estações de transição, nos meses de maio, setembro e outubro. A duração dos eventos varia pouco em termos absolutos ao longo do ano, embora tal variação seja expressiva em termos relativos. A duração dos eventos é maior nos meses da estação chuvosa e em maio e setembro (outono e primavera). Por último, o número de dias com chuva também é maior no período chuvoso e possui mínimo em agosto. Essa última variável também tem máximos locais, embora pouco expressivos, em maio e em outubro;

- Considerando a ausência de pesquisas recentes com o uso de metodologia similar à aplicada para a área de estudo, os resultados incorporam ao referencial teórico já existente sobre o clima de Maringá, informações com respaldo estatístico. Isso proporcionou, dentre outras conclusões como as apresentadas sobre tendência, evidenciar eventos expressivos de precipitação ocorrendo nas estações de transição e não somente no verão, e com duração e volumes diferentes, conforme análise interanual. A partir desses resultados é possível estimar que a variabilidade da precipitação em Maringá tem origem em sistemas atmosféricos de variadas escalas espaciais e temporais, assim como na influência da circulação oceânica sobre o clima local, sendo que este último aspecto pode ser melhor investigado, ao se incorporar a temperatura na análise.

\section{Referências}

BACK, A. J. Aplicação de análise estatística para identificação de tendências climáticas. Pesquisa $\begin{array}{lllllll}\text { Agropecuária } \quad \text { Brasileira, } & \text { v. } & 36, & \text { n. } & 5, & 717-726, & 2001 .\end{array}$ http://www.scielo.br/scielo.php?script=sci_arttext\&pid=S0100204X2001000500001\&lng=en\&nrm=iso\&tln $\mathrm{g}=\mathrm{pt}$

BERGER, W. H.; LABEYRIE, L. D. Abrupt climate change - un introduction. In: Berger, W. H.; Labeyrie, L. D. (Ed.). Abrupt climate change: evidence and implications. NATO ASI Series. Series C: Mathematical and Physical Sciences, v. 16,1987. p. 3-21.

CAVAlCANTI, I. F. A. Episódios El Niño/Oscilação Sul durante a década de 1986 a 1996 e suas influências no Brasil. Climanálise, 1996.

http://climanalise.cptec.inpe.br/ rclimanl/boletim/cliesp10a/nino.html

CHAVES, R. R.; CAVALCANTI, I. F. A. Atmospheric circulation features associated with rainfall variability over Southern Northeast Brazil. Monthly Weather Review, v. 129, 2614-2626, 2001. http://mtc- m16b.sid.inpe.br/col/cptec.inpe.br/walmeida/2003/06.06.09.30/doc/Chaves_Atmos pheric\%20circulation\%20features\%20associated

CPTEC/INPE. Banco de dados de imagens. 2019a.

http://satelite.cptec.inpe.br/acervo/goes.formulario.logic?i=br 
CPTEC/INPE. Carta sinótica. 2019b.

http://tempo.cptec.inpe.br/cartas.php?tipo=Superficie

CPTEC/INPE. Glossários. 2019c.

https://www.cptec.inpe.br/glossario.shtml\#1

GRIMM, A. M.; FERRAZ, S. E. T.; GOMES, J. Precipitation anomalies in Southern Brazil associated with El Niño and La Niña events. Journal of Climate, 11, 2863-2880, 1998.

https://journals.ametsoc.org/doi/abs/10.1175/1520-0442(1998)011\%3C2863\%APAISBA\%3E2.0.CO\%3B2

GRIMM, A. M. Clima da Região Sul do Brasil. In: Cavalcanti, I. F. A.; Ferreira, N. J.; Silva, M. G. A. J. da; Dias, M. A. F. da. (Orgs.). Tempo e clima no Brasil. São Paulo: Oficina de Textos, 2009. p. 259-275.

IBGE. Divisão do Brasil em mesorregiões e microrregiões geográficas. Rio de Janeiro: IBGE, 1990. 135

p. https://biblioteca.ibge.gov.br/visualizacao/monografias/GEBIS\%20\%20RJ/DRB/Divisao\%20regional_v01.p df

IBGE. IBGE | Cidades@ | Paraná | Maringá | Panorama. 2019a.

https://cidades.ibge.gov.br/brasil/pr/maringa/panorama

IBGE. IBGE | mapas | bases e referenciais | bases cartográficas | malhas digitais. 2019b. ftp://geoftp.ibge.gov.br/organizacao_do_territorio/malhas_territoriais/malhas_de_setores_censitarios_diviso es_intramunicipais/censo_2010/

INMET. Instituto Nacional de Meteorologia. Normais climatológicas do Brasil. Brasília, DF: Ministério da Agricultura, Pecuária e Abastecimento, 2018.

NATIVIDADE, U. A.; GARCIA, S. R.; TORRES, R. R. Tendência dos índices de extremos climáticos observados e projetados no estado de Minas Gerais. Revista Brasileira de Meteorologia, v. 32, n. 4, outdez. 2017.

http://www.scielo.br/scielo.php?script=sci_arttext\&pid=S0102-77862017000400600

PAIVA SOBRINHO, S. P.; MATOS, V. A. T. de; PEREIRA, A. P. M. S.; PIVETTA, F.; SEIXAS, G. B.; CAMPELO JUNIOR, J. H. Determinação dos parâmetros da distribuição gama e média pluviométrica decendial para estações do estado de Mato Grosso. Revista Brasileira de Meteorologia, v. 29, n. 2, 183196, 2014.

SAMPAIO, S. C.; LONGO, A. J.; QUEIROZ, M. M. F. de ; GOMES, B. M. ; VILAS BOAS, M. A. ; SUSZEK, M. Estimativa e distribuição da precipitação mensal provável no Estado do Paraná. Acta Scientiarum Human and Social Sciences, v. 28, n. 2, 267-272, 2006.

SANTOS, J. W. M. C. O clima urbano de Maringá: ensaio metodológico para cidades de porte médio e pequeno. 172 f. 1996. Dissertação (Mestrado em Geografia) - Universidade de São Paulo.

SILLMANN, J.; KHARIN, V. V.; ZHANG, X.; ZWIERS, F. W.; BRONAUGH, D. Climate extremes indices in the CMIP5 multi-model ensemble. Part 1: Model evaluation in the present climate. Journal of Geophysical Research: Atmospheres, v. 118, n. 4, 1716-1733, 2013.

https://doi.org/10.1002/jgrd.50203

SILVA, W. L. ; DERECZYNSKI, C. ; CHANG, M. ; FREITAS, M .; MACHADO, B. J. ; TRISTÃO, L. ; RUGGERI, J. Tendências observadas em indicadores de extremos climáticos de temperatura e precipitação no estado do Paraná. Revista Brasileira de Meteorologia, São Paulo, v. 30, n. 2, 2015. http://dx.doi.org/10.1590/0102-778620130622

SILVEIRA, L.M. da. Análise rítmica dos tipos de tempo no Norte do Paraná, aplicada ao clima local de Maringá-PR. 2003. 505 f. Tese (Doutorado em Geografia Física) - Faculdade de Filosofia, Letras e Ciências Humanas, Universidade de São Paulo, 2003. 
TAVARES, R. Clima, tempo e desastres. In: TOMINAGA, L. K.; SANTORO, J.; AMARAL, R. do (Orgs.). Desastres naturais: conhecer para prevenir. São Paulo: Instituto Geológico, 2009. p. 113-146.

UNISDR. The United Nations Office for Disaster Risk Redution. Terminology on Disaster, Risk, Reduction. 2009.

https://www.unisdr.org/we/inform/publications/7817

WMO - World Meteorological Organization. WMO Guidelines on the Calculation of Climate Normals. WMO n. 1203. Genebra, Suíça. 2017. 